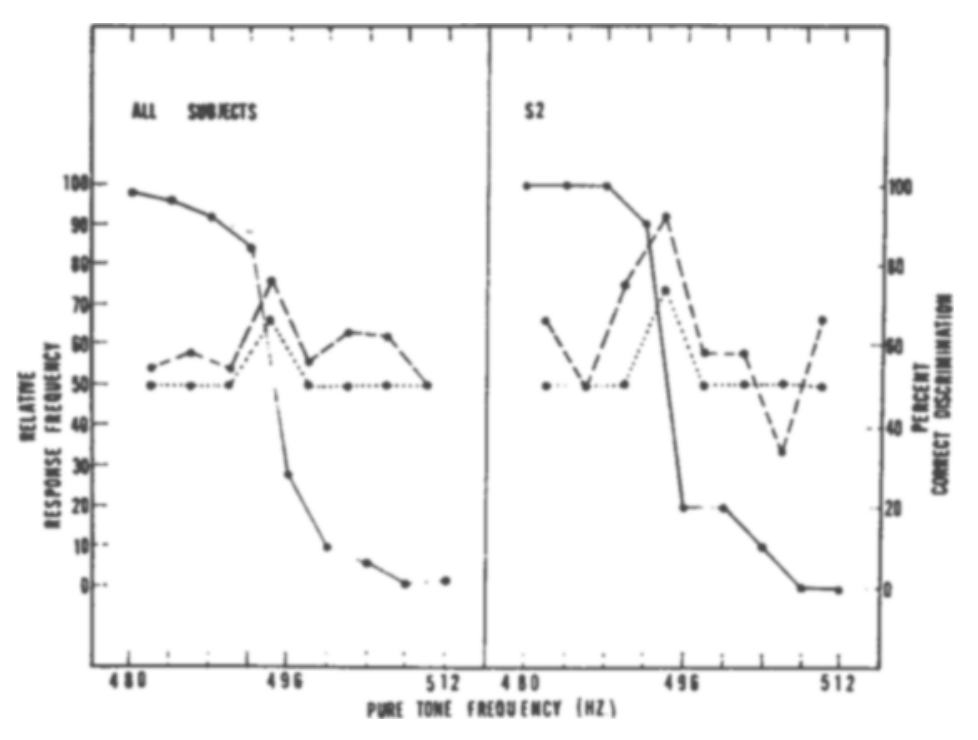

It can be seen from Fig. 1 that the predicted and obtained values are very similar and tend to covary. The obtained values are somewhat higher overall, also in accord with earlier findings (Lane, 1965).

The observation that a direct functional relationship exists between identification probabilities and discrimination probabilities on the auditory frequency continuum corroborates earlier findings comparing naming and discrimination behavior in other sense modalities. The fact that these data were obtained over a simple physical continuum supports the Lane (1965) argument that the identification. discrimination relationship is not specific to speech stimuli and therefore does not require a special mechanism involving matching vocal articulation responses for its explication.

\section{REFERENCES}

CROSS, D. V., \& LANE, H. L. An analysis of the relations between identification and discrimination functions for speech and non-speech continua. University of Michigan Behavio Analysis Laboratory Progress Report No.6, October 1964.

CROSS, D. V., LANE, H. L., \& SHEPPARD, W.C. Identification and discrimination functions for a visual continuum and their relation to the motor theory of speech perception. Joumal of Experimental Psychology, 1965, 70, 63-74.

HENNEY, K. Principles of radio ( $3 \mathrm{~d}$ ed.). New York: Wilcy, 1938.

KOPP, J., \& LANE, H. L. Hue discrimination related to linguistic habits. Psychonomic Science, 1968, 11, 61-62.

LANE, H. L. The motor theory of speech perception: A critical review. Psychological Review, 1965, 72, 275-309.

LANE, H. L. A behavioral basis for the polarity principle in linguistics. In K. Salzinger (Ed.), Research in verbal behavior and some neurophysiological implications. New York: Academic Press, 1967.

LIBERMAN, A. M., HARRIS, K. S., HOFFMAN, H. S., \& GRIFFITH, B.C. The discrimination of speech sounds within and across phoneme boundaries. Journal of Experimental Psychology, 1957, 54, 358-368.

LIBERMAN, A. M., HARRIS, K. S., KINNEY, J.

\section{D. $M c C O M B$, The Southampton, England}

The notion that GSR conditioning data are purely a function of $S$ 's awareness of relevant stimulus contingencies is challenged. An experiment is described in which, using a manifest task to disguise the true nature of the experiment from $S$, greater differential responding to the CS/in extinction) was seen in the case where $S s$ experienced conditioning trials having been informed previously of the CS-UCS contingency, than when this information was not followed by conditioning trials. The familiar finding of no conditioning without awareness is also supported.

Cognitive theorists (cf. Razran, 1955) have concluded from demonstrations of a "conditioning-like" phenomenon using GSR without a single pairing of CS and UCS (cf. Cook \& Harris, 1937; Hilgard \& Humphries, 1938) that an exclusively cognitive, perceptual phenomenon, something called "relational learning" (Razran, 1955) was being observed. Since, however, this occurs in the context of a classical learning paradigm, in which the pairing of
Fig. 1. Mean identification, discrimination, and predicted discrimination functions for 20 Ss (left) and actual values for one representative $S$ (right). Solid lines represent identification probabilities of one tone name (" $B$ "). Probabilities of the other tone name (" $C$ ") are complementary to these values. Dashed lines represent obtained per cent correct ABX discrimjnations. Dotted lines represent the per cent correct ABX discriminations predicted from identification probabilities. There were 10 presentations of each stimulus value for identification, and 12 presentations of each stimulus pair for discrimination, per $\mathbf{S}$.

A., \& LANE, H. L. The discrimination of relative onset time of the components of certain speech and non-speech patterns. Joumal of Experimental Psychology, 1961, 61, 379-388.

\title{
Cognitive and learning effects in the production of GSR conditioning data'
}

of CS and UCS (actually or threatened) is present procedurally, the phenomenon described by Pavlov (1927) would seem to be relevant as well.

On the one hand these variables have been conceptualized as dichotomous (Mandel, 1966; Mandel \& Bridger, 1967; Mowrer, 1938; Streiner \& Sanford, 1968) while on the other, effects thought to be cognitive in nature (e.g., preparatory sets) are thought to be established and modified by the manipulation of parameters relevant to learning(Grings, 1960).

The present experiment was designed to permit a description of some functional relationships whereby so-called "cognitive" as well as learning variables exert control over the dependent variable.

\section{METHOD}

Subjects were seated in a darkened, sound-attenuated chamber and instructed to attempt to maintain a pointer on a moving irregular track by means of a steering wheel directly in front of them. GSR electrodes were attached to the palm and wrist of the nonpreferred hand. Mounted on the apparatus, containing a drum with the track described thereupon, were five horizontal, equally spaced lights of different colors (red, orange, blue, green, and white). A speaker 
that produced white noise ( $100 \mathrm{~dB}$ at 18 in.) served as well to support the remote end of the steering column. Ss were informed that the effects of incidental stimulation on the fatigue curve produced by prolonged driving was being measured. The instrumental task served to: (a) direct ego-serving needs away from the crucial aspects of the experiment, (b) keep Ss oriented to the visual stimuli, and (c) maintain a roughly constant level of attention or alertness.

All control and monitoring equipment was housed in an adjoining room. An eight-channel tape reader was adapted to step once each second, and light stimuli of $1 \mathrm{sec}$ duration were presented successively at intervals (onset to onset) of 9, 12, or 15 sec. All lights were presented an equal number of times in a predetermined random order with restrictions regarding runs of any one color.

Forty-seven male engineering students were divided randomly into three groups which received the following treatments:

Group 1: Phase 1, an habituation phase, consisted of the presentation of each light five times, during which "normal" reactions to each color were assessed. Ss were then interrupted and informed that since the sudden 1 -sec burst of white noise was upsetting to some people, when it was to be presented it would be preceded immediately by an orange light. Phase 2, consisting of 15 acquisition trials at $80 \%$ reinforcement, then followed. This was followed immediately by Phase 3, consisting of five extinction trials. Intertrial intervals were 36,72 , or $108 \mathrm{sec}$, in the ratio of $7: 5: 3$, yielding a mean intertrial interval of approximately $1 \mathrm{~min}$.

Group 2: Treatment was identical to that pertaining to Group 1 with the following modifications: No Ss were informed at any point in the session of the CS-UCS contingency. Ss were subsequently divided into two subgroups on the basis of their ability (Group 2+) or inability (Group 2-) to verbalize the CS-UCS contingency. CS and UCS were presented simultaneously rather than successively, since pilot work indicated that, using a trace paradigm, no $S$ "caught on," unaided, to the relevant contingency.

Group 3: Treatment was identical to that pertaining to Group 1 with the following modifications: Ss were informed prior to Phase 1 (habituation) of the CS-UCS contingency although this did not immediately come into effect. The information, however, was not contradicted during this phase. During Phase 2 (when Groups 1 and 2 received CS-UCS pairings), Group 3 received a sensitization series in which the same stimuli were presented with identical frequencies as in Groups 1 and 2; however, the UCS (noise) was explicitly unpaired with any of the light stimuli.
Table 1

Percentage of total response magnitude elicited by the CS. (Figures in brackets denote greatest percentage of total response magnitude elicited by a control stimulus. Letter indicates its color).

\begin{tabular}{|c|c|c|}
\hline & $\begin{array}{c}\text { (Phase 1) } \\
\text { Habituation }\end{array}$ & $\begin{array}{r}\text { (Phase 3) } \\
\text { Extinction }\end{array}$ \\
\hline $\begin{array}{l}\text { Group } 1 \\
N=15 \\
\text { Group } 2+ \\
N=10 \\
\text { Group } 2- \\
N=7 \\
\text { Group } 3 \\
N=15\end{array}$ & $\begin{array}{c}13.65 X \\
(34.00-W) \\
22.20 \\
(22.20-W) \\
24.28 \\
(27.19-W) \\
X 32.46 \\
(19.97-G)\end{array}$ & $\begin{array}{c}41.34 \\
(17.19-\mathrm{R}) \\
32.25 \\
(20.75-\mathrm{B}) \\
21.86 \\
(29.12-\mathrm{R}) \\
18.68 \\
(24.92-\mathrm{G})\end{array}$ \\
\hline
\end{tabular}

$X$ - point in time when information regarding CS-UCS contingency divulged.

GSR was recorded using a Grass Model 7 polygraph and magnitude data was obtained from the paper printout.

\section{RESULTS}

An analysis of responding to the UCS in Phase 2 revealed no group differences.

Differences in responding existing among the four control stimuli are attributed to uncontrolled factors such as intensity differences and prior connotations associated with particular colors and are regarded as not bearing upon the results and interpretations presently drawn.

Each S's mean response (in ohms) per presentation of each color stimulus was calculated. Means were then transformed into percentages of the total responding by each $S$ in Phases 1 and 3. The percentages which pertain to each S's responding to each visual stimulus were summed over all members in each group and overall group means were obtained. These data are presented in Table 1.

The finding of no differences in Group 2- between habituation and extinction [Wilcoxon $T(7)=11, n . s$.] supports the familiar conclusion that lack of awareness of the CS-UCS contingency precludes the manifestation of any conditioning effect (cf. Fuher \& Baer, 1965).

Evidence for conditioning in that proportion of Group 2 which perceived, unaided, the relationship (10 of $17 \mathrm{Ss}$ ) is significant $[\mathrm{T}(10)=7, \mathrm{p}<.05]$; however, this is an unwieldy heterogeneous group which includes Ss who "caught on" on the first trial as well as those who conceivably did not perceive the CS-UCS contingency until the final trial.

The Cook \& Harris (1937) finding is seen again in Group 3(habituation). The increase in proportion of responding to the $\mathrm{CS}$ due to instructions regarding the CS-UCS contingency is significant comparing habituation data for Group 3 with that for Groups 1 and 2 combined [Mann-Whitney $\mathrm{U}(32,15)=61$, $p<.0003$, one-tailed test]. However, if the information regarding the relationship is followed by presentations of reinforced trials (Group 1) the percentage of total responding to the $\mathrm{CS}$ in extinction rises significantly above the level produced by the information alone $[U(15,15)=52$, $p<.02]$. If this information is not reinforced, the percentage falls back to "normal" levels (Group 3, extinction), this difference (habituation vs extinction) being significant as well $[\mathrm{T}(15)=3, \mathrm{p}<.01]$.

\section{DISCUSSION}

While familiar findings regarding the crucial role of awareness are supported, this is not to say that what is observed is entirely attributable to this variable. To the extent that it is not known how awareness, however defined, controls behavior, it cannot account for any present findings. These results suggest that the experiencing of CS-UCS pairings is a relevant variable in GSR conditioning insofar as information regarding the CS-UCS contingency plus the presentation of trials resulted in a greater differential responding to the CS than that attributable to the information alone. The interaction between learning and "cognitive" variables implies that attempts to provide complete explanations for the phenomenon of GSR conditioning in terms of one set of terms to the exclusion of the other will most likely be lacking in some respects, at least until the parameters of cognitive phenomenon and how they exert their effects on dependent variables of interest are better understood.

\section{REFERENCES}

COOK, S. W., \& HARRIS, R. E. The verbal conditioning of the galvanic skin response. Journal of Experimental Psychology, 1937, 21, 202-210.

FUHRER, M. J., \& BAER, P. L. Differential classical conditioning: Verbalization of stimulus contingencies. Science, 1965, 150, 1479-1481.

GRINGS, W. W. Preparatory set variables in the classical conditioning of autonomic variables. Psychological Review, 1960, 67, 243-252.

HILGARD, E. R., \& HUMPHRIES, L. G. The effect of supporting and antagonistic voluntary instructions on conditioned discrimination. Joumal of Experimental Psy chology, 1938, 22, 291-304.

MANDEL, I. J. Two levels of GSR conditioning: Interstimulus interval effects. Dissertation Abstracts, 1966, 26, 7462-7463.

MANDEL, 1. J., \& BRIDGER, W. H. Interaction between instructions and ISI in conditioning and extinction of the GSR. Joumal of Experimental Psychology, 1967, 74, 36-43.

MOWRER, O. H. Preparatory set (expectancy)-a determinant in motivation and learning. Psychological Review, 1938, 45, 62-91.

PAVLOV, I. P. Conditioned reflexes. London: Oxford University Press, 1927.

RAZRAN, G. Conditioning and perception. Psychological Review, 1955, 62, 83-95.

STREINER, D. L., \& SANFORD, J. D. Expectancy, anxiety and the GSR. Psychonomic Science, 1968, 10, 293-294.

$$
\text { NOTE }
$$

1. This research was supported by Home Office Grant No. 1/6/3/30 to Professor G. B. Trasler, Department of Psychology, University of Southampton. 